\title{
Similarities between Parents and Their Adopted Children
}

\author{
STANLEY M. GARN, STEPHEN M. BAILEY AND PATRICIA E. COLE \\ The Center for Human Growth and Development, The University of \\ Michigan, Ann Arbor, Michigan 48109
}

\begin{abstract}
KEY WORDS Parent-child correlations · Stature - Weight $\cdot$ Fat-
\end{abstract} fold - Environment - Heritability.

\begin{abstract}
As shown in 7,230 parent-child pairs (6,726 biological and 504 adoptive), adoptive parents and their adopted children tend to resemble each other in height, weight and fatfolds to an extent paralleling height, weight and fatfold resemblances of natural (biological) parents and their children. Accordingly, the magnitudes of parent-child resemblances commonly given may not be indicative of the extent of heritability of stature, weight and subcutaneous fat.
\end{abstract}

Parent-child resemblances in stature and other dimensions constitute an important bridge between the simple description of human variability and an understanding of the mechanisms involved. For parent-child stature correlations (of the order of 0.2 to $0.4)$ provide estimates of the heritability of stature and of differing magnitudes of heritability in different human populations (Mueller, '76).

Parent-child correlations, moreover, tend to change with the age of the child, leading Rao et al. to write that "heritability is a function of age or year of birth" (Rao et al., '75). Other workers have given attention to differences in parent-child correlations according to the sex of the parent that might suggest other than autosomal inheritance (Garn, '66; Garn and Rohmann, '66).

However, parents and their children share more than genes in common, and some part of parent-child resemblances in stature and other dimensions may reflect nutritional level, dietary habits and learned patterns of energy expenditure and conservation. In this event, dimensional comparison of adoptive parents and their adoptive children would go far toward clarification of the traditional parent-child resemblances in stature and other dimensions and hence to a better understanding of the mechanisms that control human variability.

Accordingly, we now present parallel data on the resemblances between biological parents and their offspring and social or adoptive parents and their adopted children.

\section{METHODS AND MATERIALS}

This study is based upon measurements of stature, weight and the triceps fatfold made between 1959 and 1960 on a total of 13,659 participants in examination round I of the Tecumseh (Michigan) Project of Michigan School of Public Health. With few exceptions, participants were of Northwest European and Central European origin. Details of the unique total-population sample are given by Napier ('62) and by Francis and Epstein ('65).

In all 7,320 parent-child pairs involved 6,726 biological parents and their serologically-verified offspring and 504 adoptive parent-child pairs. This second group included both doubly-adopted children and singly-adopted children, i.e. the adopted child of one parent of the pair.

Prior to making parent-child correlations, stature, weight and the triceps fatfold values were first normalized for age and sex, using a specially-written computer program. The resulting normalized Z-scores were then used in the calculations. Furthermore, since the magnitude of parentchild similarities is known to change with age (Rao et al., '75; Mueller, '76), agespecific correlations were arranged into four age groupings, covering the age range birth through 18 years.

In making the dimensional comparisons of biological and adoptive parent-child pairs, 
attention was given to the educational level of the parents, age-group by agegroup and also as education-corrected partial correlations. Considerable care was also employed in initial data-cleaning to remove coding and transcription errors and improbable values. In view of the findings, estimates of "heritability" were not given major attention. However, possible influences of the sex of the parent and agedependent levels of correlation were both examined in pooled correlations in the biological parent-child pairs and in the adoptive parent-child pairs as well.

\section{FINDINGS}

As shown in the table (table 1) where parent-child correlations are presented by age of the child, biological parents and their children evidence dimensional resemblances at all ages considered. This is true for 12 father-son correlations, 12 fatherdaughter correlations, 12 mother-son correlations and 12 mother-daughter correlations for stature, weight and the triceps fatfold. In view of the large sample size it is not surprising that the individual parentchild correlations are all positive and generally statistically significant. Pooling agespecific correlations for both like-sexed and cross-sexed parent-child pairs, then biological parents and their children yield correlations of 0.35 for stature, 0.26 for weight and 0.21 for the triceps fatfold (fig. 1). Comparisons may be made, therefore, with parent-child correlations we have previously reported from the Fels Longitudinal Studies (Garn, '66; Garn and Rohmann, '66) and with other studies reported in the literature where sample sizes are sufficient to provide reliable estimates of $r$ (Mueller, 76, table 2).

Taken overall, there are not great differences between father-son and motherson or father-daughter and mother-daughter correlations in these large-sample biological parent-child comparisons. There is, however, the expected tendency for the parent-child correlations to increase with the age of the child. This is true for stature, it is true for weight and especially true for the triceps fatfold where the parent-child correlations are far higher at age 15-18 $(r=0.30)$ than in the first four years of life $(r=0.10)$. For all three measurements taken together, parent-child correlations average 0.22 for the first four years, 0.28 for the fifth to ninth years, 0.29 for the tenth to fourteenth years and 0.34 through the eighteenth year - a highly consistent trend and one significant by various tests.

When the 504 adoptive parent-child pairs are next considered, correlations are again significant overall. Pooling the ages, then, adoptive parent-child correlations are the order of 0.29 for stature, 0.16 for weight and 0.19 for the triceps fatfold (fig. 1). While these correlations are lower than the comparable pooled correlations for the biological parent-child pairings, they are not vastly lower and they do not approach the theoretical value of 0.0 that would be expected for adoptive parents and their totally unrelated adopted children were stature, weight and fatfold thickness subject to purely genetic control mechanisms. Reviewing the 36 parent-child correlations and the correlations pooled for each variable, no consistent tendency for age-associated increase is evident in the adoptive parent-child pairs either upon direct examination or by pooling the age groupings in various ways. The important point, therefore, is the magnitude of adoptive parentchild correlations for some 504 adoptive parent-child pairs as contrasted with the correlations for 6,726 biological parentchild pairs.

In making these comparisons of biological parents and their progeny and adoptive parents and their children, careful attention was given to educational level of the parent for each of the four age groupings involved. However, no systematic differences emerged upon inspection of the frequency distribution of the coded educational variable. In similar fashion, partial correlations correcting zero-order parentchild correlations for educational level of the parent did not differ from the zeroorder correlations by more than 0.03 overall. Accordingly, therefore, we can safely report that adoptive parent-child correlations for stature, weight and the triceps fatfold are surprisingly high as compared with biological parent-child correlations from the same population sample. Moreover, these comparisons of biological and adoptive parent-child pairs derived from 


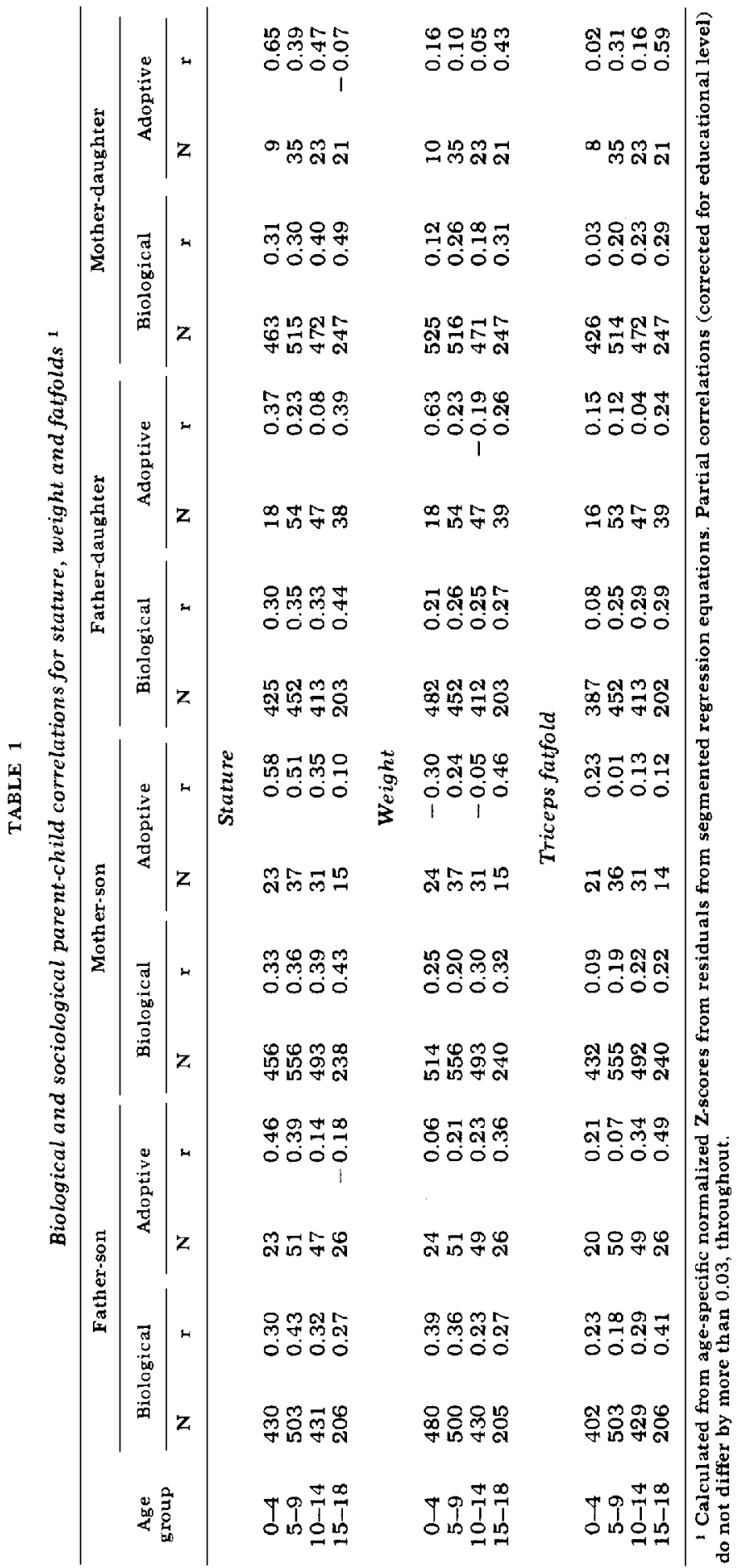




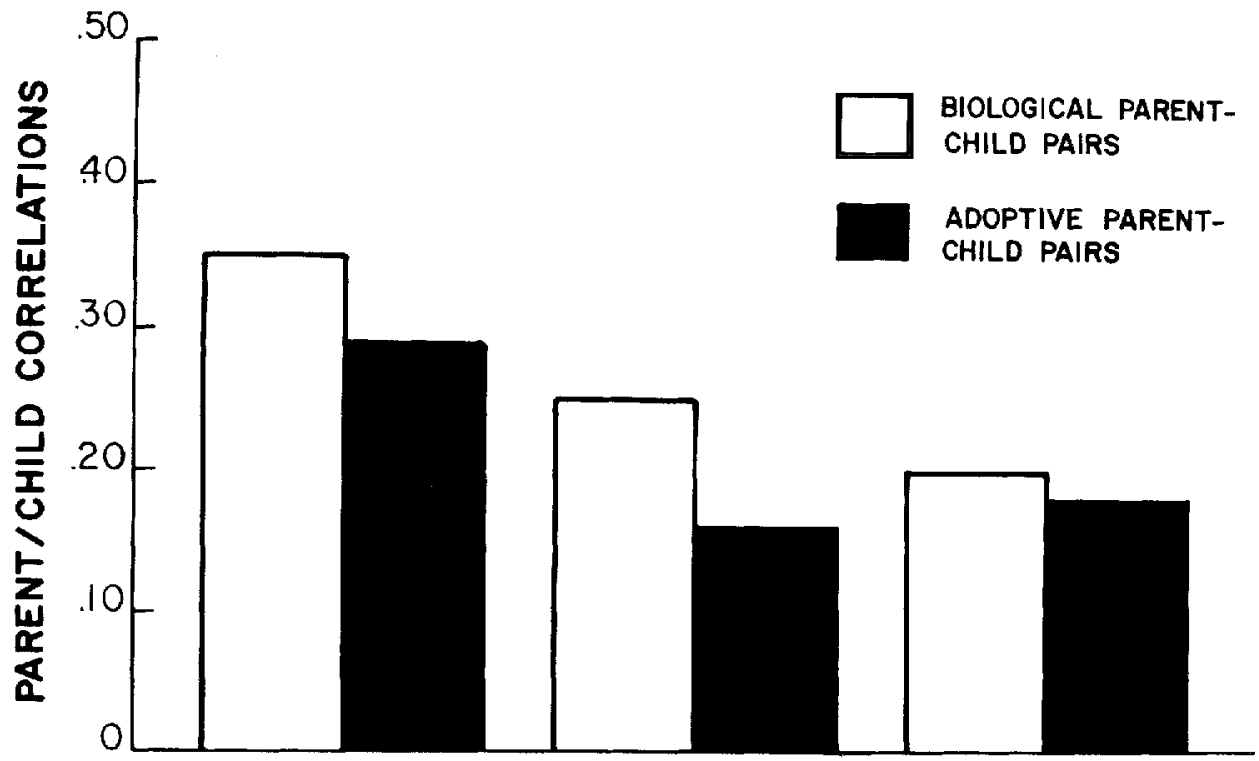

\section{STATURE}

Fig. 1 Comparison of biological parent-child correlations (unshaded) and adoptive parentchild correlations (solid) for stature, weight and the triceps fatfold using pooled values of $r$, calculated from the mean $z$-transforms of $r$. Adoptive parent-child correlations are surprisingly close to biological parent-child correlations for length, mass and outer fatness.

the same extended population (in a totalcommunity sample) are not affected by the level of parental education or associated economic variables.

\section{DISCUSSION}

The findings in this new study go far beyond the conventional questions of statistical significance and the magnitude of parent-child correlations. Of course, the trends are highly significant overall, the parent-child correlations approximate 0.25 , and there is an increasing level of $r$ with age of the child in the biological parentchild pairings. However, the major discovery is that adoptive parent-child pairs, while less similar than the biological parent-child pairs, still evidence overall resemblances in (a) stature, (b) weight and (c) the triceps fatfold. The implications to the understanding of human variability are considerable.

Given these findings, based on 6,726 biological parent-child pairs and 504 adoptive parent-child pairs, there is the question of artifact or sampling. Given the sample size, large by most standards, a statistical "fluke" is unlikely, since the trends are repeated for three technicallyindependent measures. Given the close matching of biological and adoptive parents with respect to educational level, the parent samples are obviously not drawn from grossly different statistical "populations." In the biological parent-child pairings, the correlations may be affected by a slight degree of inbreeding in the Tecumseh (Michigan) population and by homogamy (assortative mating) with respect to body size. Homogamy might also inflate correlations between adoptive parents and their children, where the child is the biological child of one parent, carefully excluded from the adoptive parent-child correlations. There is also the probabilistic question of whether adoption agencies could have matched parent and adoptive child with respect to stature, weight and the triceps fatfold even very early in life.

At the same time we may cite the growing indication that families share a common dietary and common attitudes toward eating. Much evidence that we have gained 
from the Ten-State Survey of 1968-1970 indicates family-line similarities in serum and urinary vitamins, in food-intake levels and in levels of fatness. It is interesting, moreover, that there are conspicuous parent-child and spouse correlations in such variables as the DMFT (decayed-missingfilled-teeth), all indicating that living together and eating together brings about many similarities (Garn and Pao, '68; Garn and Clark, '74; Garn et al., '74; Garn et al., '75; Garn and Clark, '76a; Garn and Clark, '76b; Garn, Clark and Guire, '76; Garn, Rowe and Clark, '76).

Now these new findings do not contradict the very obvious fact that tall people have tall children and that short people beget short children. They do suggest, however, that some part of parent-child resemblances in anthropometric dimensions is not genetically determined and that some part of sibling resemblances in size comes from living together. To the extent that this is true, estimates of heritability $\left(h^{2}\right)$ as presently calculated from parent-child and sibling correlations may not reflect genetic influences alone. While we are tempted to calculate new estimates of heritability, from our obviously-large sample, corrected for adoptive parent-child resemblances, even more information is now becoming available in the course of data analysis. With more information on parentchild, adoptive parent-child, sibling and sociological (adopted) sibling resemblances from the later examination rounds of the Tecumseh Project, we should be in a position to provide such estimates of $h^{2}$. By taking age at adoption and duration of adoption into account, further corrections should be practicable. The fact that parent-child similarities change with the age of the child may then be less difficult to explain than is the current situation.

It is axiomatic that human dimensional variability has a genetic component. In the past, parent-child and sibling correlations have together been used to estimate the magnitude of the genetic component with no great attention to the common environment. Studies such as these (including adoptive parent-child comparisons) along with classic migration studies and measures of the secular (generational) trend will help to apportion the genetic and nongenetic sources of human dimensional vari- ability. Surely this is a key step in the progress of our discipline.

\section{ACKNOWLEDGMENTS}

This study was supported by Grant HD 09538 (Socioeconomic and Genetic Determinants of Obesity) from the National Institutes of Health. We appreciate the assistance of Wendy Carmen in completing the family line tapes and Kenneth E. Guire for his extensive knowledge of MIDAS. The manuscript was completed by Alys Yeh.

\section{LITERATURE CITED}

Francis, T., Jr, and F. H. Epstein 1965 Epidemiological research in a total, natural community, Tecumseh, Michigan. Milbank Mem. Fund. Quart., 43: 333-342.

Garn, S. M. 1966 Body size and its implications. In: Review of Child Development Research, 2. L. W. and M. L. Hoffman, eds. Russell Sage Foundation, New York, pp. 529-561.

Garn, S. M., and C. G. Rohmann 1966 Interaction of nutrition and genetics in the timing of growth and development. Pediatric Clinics of North America, 13: 353-379.

Garn, S. M., and E. M. Pao 1968 Nutritional problems and nutritional solutions in long-term studies of growth and aging. In: Nutrition in a Mod World, Report of the 9th Conference on Human Nutrition, the Ohio State University, Columbus, Ohio, pp. 33-46.

Garn, S. M., and D. C. Clark 1974 Economics and fatness. Ecol. Food Nutr., 3: 19-20.

Garn, S. M., G. M. Owen and D. C. Clark 1974 Ascorbic acid: the vitamin of affluence. Ecol. Food Nutr., 3: 151-153.

Garn, S. M., D. C. Clark and B. M. Ullman 1975 Does obesity have a genetic basis in man? Ecol. Food Nutr., 4: 57-60.

Garn, S. M., D. C. Clark and K. E. Guire 1976 Husband-wife similarities in hemoglobin levels. Ecol. Food Nutr., 5: 47-50.

Garn. S. M., and D. C. Clark 1976a Trends in fatness and the origins of obesity. Pediatrics, 57 : $443-456$.

1976b Family-line origins of obesity. In: Second Wyeth Nutrition Symposium. L. A. Barness, ed., Wyeth Laboratories, Philadelphia, pp. 3-13.

Garn, S. M., N. H. Rowe and D. C. Clark 1976 Parent-child similarities in dental caries rates. J. Dent. Res, in press.

Mueller, W. H. 1976 Parent-child correlations for stature and weight among school aged children: a review of 24 studies. Human Biol., 48 : 379-397.

Napier, J. A. 1962 Field methods and response rates in the Tecumseh community health study. Am. J. Pub. Health, 52: 208-216.

Rao, D. C., C. J. Maclean, N. E. Morton and S. Yee 1975 Analysis of family resemblance. V. Height and weight in northeastern Brazil. Am. J. Hum. Genet., 27: 509-520. 